\title{
Factors determining the utilization of healthcare facilities in a semi-urban setting in Kwara State Nigeria
}

\section{DOI: http://doi.org/10.26758/7.1.9}

Oluyemi Joseph (1) Abubakar Muhammed (1) Abdullateef Raji (1) Akindele Ibimidu (1) Adejoke Joseph (2) Kadiri Kehinde (3)

(1) Department of Sociology, University of Ilorin, Ilorin, Nigeria.

(2) Department of Medical Microbiology and Parasitology, Bowen University Iwo, Nigeria.

(3) Department of Mass Communication, University of Ilorin, Nigeria

Address correspondence to: Joseph Oluyemi, Department of Sociology, Faculty of Social Sciences, University of Ilorin, Kwara State Nigeria. Phone number: +234/018034205013. Email: josepholuyemi1@gmail.com

\begin{abstract}
Objectives. The presence of healthcare facilities alone is not a requisite for the utilization of such facilities, but a function of factors predisposed to end users. This study examined the factors determining the choice of healthcare facility utilization among residents of Eyenkorin in Asa Local Government Area of Kwara State Nigeria. The objective was to identify the most utilized healthcare facility in the studied area and the reasons for choosing to utilize certain health facilities among the participants.

Material and methods. Data was retrieved through self and interviewer-administered questionnaire, involving 358 consenting participants that were selected through a two-stage sampling method implying convenience and random sampling techniques.

Results: General hospital was mostly utilized by the studied population, representing the option of over one-fourth of the participants (28.5\%). This was closely followed by Private hospital (24.6\%), Health centers (18.4\%), Teaching hospital (10.1\%), Spiritual homes (7.8\%), Traditional homes (4.5\%), Patent medicine sellers (3.9\%), and Maternity homes $(2.2 \%)$. The choice of health facility utilized was informed by effective treatment, quality service, cost, attitude of health workers, professional competence, waiting time, and distance, in that order.

Conclusion and recommendations: The study concluded that distance is not essentially a barrier to healthcare facility utilization. It also concluded that there is a growing trend towards private healthcare facilities utilization among Nigerians when this result is juxtaposed with previous studies conducted in other locations in the country. The study recommended improved healthcare capacity building for government hospitals and provision of health insurance scheme for the people.
\end{abstract}

Keywords: Healthcare Facility; Utilization; General hospital; Private hospital; Health-SeekingBehaviour.

\section{Introduction}

Healthcare utilization has been defined by Awoyemi, Obayelu \& Opaluwa (2011) as the use of healthcare services by the people. The choice of healthcare facility among people may vary from person to person and from place to place depending on various factors pre-disposed to the end users. Although-good utilization of health services in any society serves to improve the quality of 
people's health, studies have shown that healthcare utilization by people depends on availability, quality of service, socio-economic status of the people and personal characteristics of the users (Chakraborty et al., 2005; Manzoor et al., 2009; \& Onah et al., 2009).

In Nigeria, the healthcare delivery system is a blend of both public and private healthcare providers. Healthcare provision is the responsibility of the three tiers of government with the private sector also playing along (Akhtaw, 1991). The federal government plays the role of controlling the affairs of the tertiary healthcare system while the state government manages the various secondary healthcare delivery systems and the local government focuses on supervision of primary healthcare services. In the private sector, healthcare delivery is broadly categorized into those that provide primary care (general practitioners), those that provide secondary care, and those that provide both primary and specialist care (Uchendu, Ilesanmi \& Olumide, 2013).

Before the advent of modern medicine in Nigeria, traditional medicine was the main system of healthcare delivery. Healthcare delivery services during this time were offered by herbalists, divine healers, soothsayers, midwives, spiritualists, bone setters, mental health therapists, and surgeons (Awoyemi, Obayelu \& Opaluwa, 2011). The first record of modern medical services in Nigeria was discovered during the various European expenditures in the early-to-mid nineteenth century, as being provided by doctors brought by explorers and traders to cater for the well-being of the Europeans, while the natives were left to die from their diseases (Chuke, 1988).

However, after more than a century since those European explorers left the shores of Nigeria, the story seems not to have changed. There seem to persist challenges accessing modern healthcare services by the people. A health survey conducted in Nigeria in 2008 revealed that the majority of the people in the country have no health insurance coverage to cater for their health bills (***Nigerian Population Commission, 2009), which suggests that a large number of the people in the country pay for their health bills from their pocket (Out of Pocket). This, however, connotes that utilization of healthcare facilities by the people in the country would depend largely on their socioeconomic status, thereby largely informing their choice of healthcare facility utilization.

Studies conducted in and around Nigeria over the years have shown that the choice of healthcare facility utilization depends on the health-seeking behavior of the people and many other factors pre-disposed to the people. For instance, a study carried out in Sagamu, South-West Nigeria, revealed that private hospitals, teaching hospitals, patent medicine sellers, and maternity homes, in that order, were the most preferred type of health facilities due to competence, effective treatment, promptness of service and quality of service (Abiodun \& Olu-Abiodun, 2014). A related study conducted in Ilorin, North-Central Nigeria, also revealed that private for-profit health facility was the most preferred healthcare facility, which was informed by the promptness of service and availability of drugs (Abodunrin et al., 2010).

A further study conducted in South-Eastern Nigeria has also suggested that patent medicine sellers were mostly utilized (Uzochukwu \& Onwugekwe, 2004). However, Tanimola \& Owoyemi (2009) have found out that cost was a major determinant of health-seeking behaviour of people in Ayangba North Central Nigeria, but Awoyemi, Obayelu \& Opaluwa (2011) have argued that the choice of healthcare facility utilization in the area is greatly informed by the waiting time, especially in government-owned hospitals. They argued further that long queues are found in such hospitals, affecting the turnaround time for treatment and complacency on the part of the health workers as a result of having had to attend to many patients daily.

Katung (2001), Chukwuani et al. (2006), Sule et al. (2008) have also suggested that poor quality of services and poor attitude of staff are the major contributing factors responsible for the underutilization of healthcare facilities in developing countries. In addition, the competing nature of traditional medicine and traditional medicine practitioners with that of the modern medicine and 
medical doctors is also a major concern that is posing a threat to the utilization of modern healthcare facilities in the country. A survey conducted in Benin City in Edo State, South-South Nigeria in 1998, revealed that, for every signpost that indicated modern healthcare facility in the city, there were also three others that indicated traditional health facility (Awoyemi, Obayelu \& Opaluwa, 2011). This suggests that quite a number of people seek medical attention in more of traditional medicine and spiritual homes than hospitals and other modern medical facilities in the country.

Various explanations have been put forward by theorists to explain the determinants of healthcare facility utilization among people. Anderson (1968), for instance, in his Healthcare Utilization Model identified three basic factors that may determine the utilization of health facility by people. The first one he identified is called the propensity factor, suggesting that an individual will likely utilize a health facility if he/she believes that such health facility will be useful for his/her treatment. The second factor called enabling factor includes access to health insurance, family and community support, as well as the location of the individual, while the third factor, called the basic need factor, which entails perception of the need for health services, is socially evaluated.

Rosenstock \& Becker (1994) on the other hand came up with the Health Belief Model, which is centered on four basic assumptions. The first assumption suggests that an individual will seek health service if he or she believes he/she is vulnerable to disease. Secondly, health facility utilization depends on the severity of the illness, while the third assumption contends that an individual will seek healthcare service where he/she can get the best service at the minimum cost. However, the last assumption suggests that individuals' choice of healthcare facility utilization depends on influence from friends, family members and the media. It is against this background that this study examines the factors determining the utilization of healthcare facilities in Eyenkorin, Kwara State, Nigeria.

\section{Methods}

The study was conducted in Eyenkorin, a suburb of Ilorin, the capital city of Kwara State, North-Central Nigeria. Eyenkorin is located in Asa Local Government Area of Kwara State, one of the sixteen Local Government areas of Kwara State. The town is bordered by Ilorin city and Afon, the headquarters of Asa Local Government. It is a nodal town that links some part of the South-West Nigeria with Northern Nigeria. The town is inhabited by settlers from various cultures, mostly from the Yoruba, Hausa, and Ibo tribes' majority of who are from the Yoruba tribe. A large number of the inhabitants are traders, trading in consumables and engaging in other petty trading, while others engage in peasant farming and transport business. The settlement is about five minutes' drive from the center of the city of Ilorin. It is a dispersed settlement with many houses located far apart from one another and littered with shops. Eyenkorin has one district health center, two clinics and maternity homes (http://kwarastate.gov.ng/asa/). There is also a number of patent medicine stores scattered around the town.

A total of 358 consenting participants from the age of 18 years and above were involved in the study. The study employed a two-stage sampling method, which involved first convenience sampling technique and thereafter random sampling of participants. Information was gathered through a self-administered questionnaire for the participants who are literate and intervieweradministered questionnaires for those participants who are not literate. Four research assistants were recruited to administer the questionnaires and to explain the content of the questionnaire to the participants for clarity. The questionnaire contained questions on participants' socio-demographic factors, participants' healthcare facility most utilized and participants' reasons for utilizing a 
particular health facility. Data retrieved from the field was analyzed using the Statistical Package for Social Science (SPSS 17.0), while results were presented with tables and simple percentages.

\section{Results}

Table 1. Socio-Demographic Factors of Participants

\begin{tabular}{|l|l|l|}
\hline Socio-demographic variables & Frequency & Percentage (\%) \\
\hline Sex & & \\
\hline Male & 212 & $(59.2)$ \\
\hline Female & 146 & $(40.8)$ \\
\hline Total & 358 & $(100.0)$ \\
\hline Age in years & & \\
\hline 18-20years & 52 & $(14.5)$ \\
\hline 21-30years & 170 & $(47.5)$ \\
\hline 31-40years & 58 & $(16.2)$ \\
\hline 41-50years & 64 & $(17.9)$ \\
\hline $51-60$ years & 14 & $(3.9)$ \\
\hline Total & 358 & $(100.0)$ \\
\hline Marital Status & & \\
\hline Single & 68 & $(19.0)$ \\
\hline Married & 272 & $(76.0)$ \\
\hline Widowed/ Divorced & 18 & $(5.0)$ \\
\hline Total & 358 & $(100.0)$ \\
\hline Religion & & \\
\hline Christianity & 66 & $(26.8)$ \\
\hline Islam & 262 & $(73.2)$ \\
\hline Total & 358 & $(100.0)$ \\
\hline Occupational Status & & \\
\hline Unemployed & 22 & $(6.1)$ \\
\hline Self-Employed & 208 & $(58.1)$ \\
\hline Professional & 18 & $(5.0)$ \\
\hline Skilled Labour & 64 & $(17.9)$ \\
\hline Unskilled Labour & 46 & $(12.8)$ \\
\hline Total & 358 & $(100.0)$ \\
\hline Educational Status & & \\
\hline None & 72 & $(20.1)$ \\
\hline Primary & 67 & $(18.7)$ \\
\hline Secondary & 192 & $(53.6)$ \\
\hline Post- Secondary & 11 & $(3.1)$ \\
\hline Tertiary & 16 & $(4.5)$ \\
\hline Total & 358 & $(100.0)$ \\
\hline Tribe & & \\
\hline Yoruba & 324 & $(91.0)$ \\
\hline Ibo & 3 & $(0.8)$ \\
\hline Hausa & 16 & $(4,5)$ \\
\hline Tiv & 5 & $(1,4)$ \\
\hline & & \\
\hline
\end{tabular}




\begin{tabular}{|l|l|l|}
\hline Others & 10 & $(2.3)$ \\
\hline Total & 358 & $(100.0)$ \\
\hline
\end{tabular}

Researchers' Survey 2016

Table 2. Healthcare Facility Most Utilized by Participants

\begin{tabular}{|l|l|l|}
\hline Healthcare Facility & Frequency & Percentage (\%) \\
\hline General Hospital & 102 & $(28.5)$ \\
\hline Private Hospital & 88 & $(24.6)$ \\
\hline Patient Medicine Sellers & 14 & $(3.9)$ \\
\hline Health Centers & 66 & $(18.4)$ \\
\hline Teaching Hospital & 36 & $(10.1)$ \\
\hline Spiritual Home & 28 & $(7.8)$ \\
\hline Maternity Home & 8 & $(2.2)$ \\
\hline Traditional Homes & 16 & $(4.5)$ \\
\hline Total & 358 & $(100.0)$ \\
\hline
\end{tabular}

Researchers' Survey 2016

Table 3. Reasons for utilization of health facility

\begin{tabular}{|l|l|l|}
\hline Reasons for Utilization & Frequency & Percentage (\%) \\
\hline Effective Treatment & 96 & $(26.8)$ \\
\hline Quality Service & 78 & $(21.8)$ \\
\hline Cost & 72 & $(20.1)$ \\
\hline Attitude of Health Workers & 34 & $(9.5)$ \\
\hline Professional Competence & 30 & $(8.4)$ \\
\hline Waiting time & 30 & $(8.4)$ \\
\hline Distance & 18 & $(5.1)$ \\
\hline Total & 358 & $(100.0)$ \\
\hline
\end{tabular}

Researchers'Survey 2016

Table 1 shows that $59.2 \%$ of the participants were male, while $40.8 \%$ were female. $47.5 \%$ of the total sample was within the age bracket of 21-30 years. Consequently, $76.0 \%$ are married, while $19.0 \%$ of the studied population was single and $5.0 \%$ are widowed. Furthermore, $26.8 \%$ of the participants were Christians, while $73.2 \%$ were Muslims. In addition, $58.1 \%$ were self-employed, $17.9 \%$ were skilled laborers, $12.8 \%$ were unskilled laborers, $5.0 \%$ were professionals, while $6.1 \%$ were unemployed. Regarding the educational status of the participants, $20.1 \%$ had no formal education, $18.7 \%$ had only primary education, $53.6 \%$ had secondary school education, and $3.1 \%$ had only post-secondary education, while $4.5 \%$ of the participants' have tertiary education. As regards tribal affiliation, sample distribution was the following: Yoruba tribe (91.0\%), Hausa tribe (4.5\%), Tiv tribe (1.4\%), Ibo tribe (0.8\%), and other minor tribes $(2.3 \%)$.

As displayed in table 2, the utilized healthcare facilities were: general hospital $(28.5 \%)$, private hospitals $(24.6 \%)$, patent medicine stores $(3.9 \%)$, health centers $(18.8 \%)$, teaching hospital $(10.1 \%)$, spiritual homes $(7.8 \%)$, maternity home $(2.2 \%)$, and traditional homes $(4.5 \%)$.

According to table 3,26.8\% of the participants made their choice of health facility based on the effectiveness of treatment; other reasons were as follows: quality of service $(21.8 \%)$, cost $(20.1 \%)$, attitude of health workers $(9.5 \%)$, professional competence $(8.4 \%)$, little waiting time $(8.4 \%)$, and distance from their home $(5.1 \%)$. 


\section{Discussion}

The study has been able to assess the options for using certain health facility services among the participants and the reasons behind their choices. Result, however, showed that the most utilized healthcare facility among residents in the studied area is the General hospital situated in Ilorin and Afon, representing over one-fourth of the participants. This was closely followed by the Private hospital accounting for about one-fourth of the participants while Health centers, Teaching hospital, Spiritual homes, Traditional homes, Patent medicine sellers and Maternity homes followed, in that order. The choice of health facility among the participants was informed by effective treatment, quality service, cost, the attitude of health workers, professional competence, waiting time, and distance in that order.

These findings are, however, not in agreement with those reported in the earlier study conducted by Abodunrin, et al. (2010) in Ilorin, North-Central Nigeria, that showed that private-forprofit health facilities were the most preferred healthcare facilities by the people. In addition, the findings of this study come to contradict the results of the study carried out by Abiodun \& OluAbiodun-(2014), in Sagamu South-West Nigeria, which found out that a private hospital was more preferred by the people. The current study revealed that people are gradually turning towards private healthcare facilities and that distance is not necessarily a barrier to healthcare facility utilization if people consider that they will get good treatment for their illness.

\section{Conclusion and recommendations}

The study examined the factors determining the utilization of healthcare facilities in Eyenkorin, a suburban community in Asa Local Government Area of Kwara State, North Central Nigeria. 358 consenting participants from 18 years and above were included in the study, being conveniently and randomly sampled from the studied population. Primary data were retrieved through a self and interviewer-administered questionnaire that contained both open and closed questions. Results showed that the most utilized healthcare facility among the respondents is the General hospital in the neighboring towns of Afon and Ilorin, which was closely followed by the private hospital. According to the study, participants' choice of health facility was informed by effective treatment, quality service, cost, the attitude of health workers, professional competence, waiting time, and distance, in that order.

The study revealed that distance is not essentially a barrier to healthcare facility utilization; it also revealed that there is a growing trend towards private healthcare facilities as a choice of medical services among the people of Nigeria, a result also supported by previous studies conducted in other locations in the country. The study, therefore, recommends that government should improve capacity building for the government hospitals by equipping them with updated armamentarium to meet the current health needs of the people. It also recommends that government hospitals should reduce the bureaucratic process to the barest minimum to avoid delay in delivering medical services, since waiting time is an important factor influencing the use of healthcare facilities, especially in government owned hospitals, such as general and teaching hospitals and primary health centers. Finally, the government should make health insurance available to the people by subsidizing their health bills and thus reducing the financial burden on individuals. 


\section{Bibliography}

1. Abiodun, O.A., Olu-Abiodun, O.O., 2014. The Determinants of Choice of Health Facility in Shagamu, South-West, Nigeria. Scholars Journal of Applied Medical Sciences (SJAMS), 2(1), pp.274-282.

2. Abodunrin, O.L., Bamidele, J.O., Olugbenga-Bello, A.J., Parakoyi, D.B., 2010. Preferred Choice of Health Facilities for Healthcare among Adult Residents in Ilorin Metropolis, Kwara State, Nigeria. International Journal of Health Research, 3(2), pp.79-86.

3. Akhtaw, R., 1991. Healthcare Pattern and Planning in Developing Countries. New York /Westport/Connecticut/London: Greenwood Press.

4. Anderson, R., 1968. A Behavioural Model of Family Use of Health Services. Chicago: Center for Health Administration Studies, Graduate School of Business, University of Chicago.

5. Awoyemi, T.T., Obayelu, O.A., \& Opaluwa, H.I., 2011. Effect of Distance on Utilization of Healthcare Services in Rural Kogi State, Nigeria, Journal of Human Ecology, 35(1), pp.1-9.

6. Chakraborty, N., Islam, M.A., Chowdbury, R.I., Barl, W.W., Akhter, H.H., 2005. Determinants of the Use of Maternal Health Services in Rural Bangladesh, Health Promotion International, 18(4), pp.327-327.

7. Champion, V. L. and Skinner, C.S., 2008. The health belief model. In: K. Glanz, B.K. Rimer, and K. Viswanath, eds. Health Behaviour and Health EducationTheory: Theory, Research and Practice (4 ${ }^{\text {th }}$ ed), San Francisco, C.A: Jossey-Bass, pp.45-62.

8. Chukwani, C.N., Olugbodi, A., Akuko, E.E., Odebunmi, A., Ezelto, E., Ugbene, E. 2006. A Baseline Survey of the Primary Healthcare System in Southern-Eastern Nigeria, Health Policy, pp.182-200.

9. Guendelman, S., 1991. Healthcare Users Residing on the Mexican Border. What Factors Determine Choice of the U.S. or Mexican Health System? Med Care, 29(5), pp. 419-429. [online] Available at: <http:// Kwarastate.gov.ng/asa/> [Accessed 10 august 2016].

10. Katung, P.Y., 2001. Socio-economic Factors Responsible for Poor Utilization of Primary Healthcare Services in a Rural Community in Nigeria. Nigerian Medical Journal, 10(1), pp.2829.

11. Manzoor, I., Hashmi, N.R., Mukhtar, F., 2009. Determinants and Pattern of Healthcare Service Utilization in Postgraduate Students. Journal of Ayub Medical College Abbottabad, 21(3), pp.100-105.

12. Onah, H, Ikeako, L., Ilobachie, G., 2009. Factors Associated with the Use of Maternal Service in Enugu, South Eastern Nigeria. Social Science and Medicine, 63(7), pp.1870-1878.

13. Portes, A., Kyle, D., Eaton, W.W., 1992. Mental Illness and Help Seeking Behaviour among Meriel Cuban and Haitian Refugees in South Florida. Journal of Health and Social Behavior, 33(4), pp.283-298.

14. Rosenstock, I.M., Strecher, V.J \& Becker, M.H., 1994. The Health Belief Model and HIV risk Behaviour Change. In: R.J. Diclemente \& J.L. Peterson, eds. Preventing AIDS: Theories and Methods of Behavioural Interventions, New York, NY: Plenium Press, pp.5-24.

15. Sule, S.S., Ijadumola, K.T., Onayade, A.A., Fatusi, A.O., Soetan, R.O., Connell. F.A., 2008. Utilization of Healthcare Facility: Lessons for a Rural Community in South Western Nigeria. Nigerian Medical Journal, 17(1), pp.98-106.

16. Tanimola, M.A., Owoyemi, J.O., 2009. Health Seeking Behaviour in Ayingba, North Central Nigeria. Research Journal of Medical Research, 3(2), pp.47-51. 
17. Uchendu, O.C., Ilesanmi, O.S \& Olumide, A.E., 2013. Factors Influencing the Choice of Healthcare Providing Facility among Workers in a Local Government Secretariat in South Western Nigeria. Annals of Ibadan postgraduate medicine, 11(2), pp.87-95.

18. Uzochukwu, B, S, C., \& Onwujekwe, O.E., 2004. Socio-Economic Difference in Health Seeking Behaviour for the Diagnosis and Treatment of Malaria. A case of Four Local Government Areas Operating the Bamako Initiated Programme in South-East Nigeria. International Journal for Equity in Health, 3(1), p.6.

19. Wolinsky, F.D., 1988. Seeking and Using Health Services. In: The sociology of health: principles, practitioners, and issues. (2nd ed.) Belmont, Calif.: Wadsworth, pp. 117-144.

20. Wolinsky, F.D., \& Johnson, R.J., 1991. The use of Health Services by Adults. Journal of Gerontology, 46(6), pp.345-357.

21. Zwi, A.B., Brugha, R. and Smith, E., 2001. Private Healthcare in Developing Countries, British medical journal, 323, pp.464-466.

22. ***Nigerian Population Commission, 2009. Nigeria Demographic and Health Survey 2008, Abuja. [online] Available at: http://www.dhsprogram.com/pubs/pdf/FR222/FR222.pdf [Accessed 03 november 2016]. 